In No. 406 of the Observatory (p. 1о1, February) $\mathrm{Mr}$. Evershed discusses the same subject from the observations made at the Kodaikanal Observatory. Dealing with the water-vapour lines of intensity $\mathrm{I}$ or more given by Rowland between $\lambda 5^{8} 5^{\circ}$ and $\lambda 6000$, seventy in all, he finds that thirteen are not shown on his plates, forty-two are absolutely unaffected, scven are weakened, and eight are strengthened. Of the latter, four are only doubtfully strengthened; in two the strengthening is shown to be due to close titanium companions, and two are decidedly darkened. Mr. Evershed concludes that the weight of evidence is against the probability of the existence of steam in sun-spots, but, in commenting on this conclusion, Father Cortie points out that the conditions of observation at Stonyhurst and Kodaikanal were dissimilar, that the watervapour lines recorded as strengthened at both places stil have to be accounted for, and that the collateral evidence from the laboratory must also be taken into account.

The Spectrum and Form of Comet Morehouse.-The Astrophysical Journal for January (No. I, vol, xxix.) contains three papers dealing with Morehouse's comet, Igo8c In the first of these Prof. Frost and Mr. Parkhurst describe and discuss two series of spectrograms taken with objective-prism or with slit spectrographs, respectively, at the Yerkes Observatory. As the scale of the spectra is in each case very small, $\mathrm{H} \beta$ to $\mathrm{H} \theta$ covers about $3 \mathrm{~mm}$., the wave-lengths are only approximate, but comparisons with the hydrogen lines in the spectrum of Vega, taken on the same plate with the "slit" spectra, permitted the recognition of several of the cometary condensations.

The results differ from those previously published by MM. Pluvinel and Baldet in that the Yerkes observers find the third and fourth "carbon" (hydrocarbon?) bands whilst the Juvisy observers did not. Again, the $\mathrm{CN}$ band at $\lambda 4^{2} 16$ could not be detected on the Yerkes spectrograms, whereas the Juvisy observers found that cyanogen was fully represented; both sets of observations agree on the absence of continuous spectrum, but are not in agreement in the matter of the wave-lengths of the bands. On the other hand, the Yerkes wave-lengths agree with those of MM. Deslandres and Bernard, but the latter were unable to identify the "carbon" bands, and they found a continuous spectrum on all their plates.

A study of the relative intensities of the spectra of the head and of the streamers leads to some important results. First, of the monochromatic images of the head, those at $\lambda \lambda \quad 471$ and 388 are strong, but no corresponding tail images are shown, or are very weak, thus indicating that the matter producing these radiations is mainly confined to the comet's head. Again, the tails diverging at different angles are shown in the same monochromatic images, thus indicating that they are composed of the same materials.

The second paper is by Prof. Barnard, and in it he describes his latest photographs of the comet. The changes in form which occurred in the tail strengthen his belief that the ejected matter met with resisting media, probably meteor swarms, in space.

Spectrograms, obtained with a slit spectrograph at the Lick Observatory, are described by Prof. Campbell and Dr. S. Albrecht in the third paper. They recognise the different edges of the third and fourth carbon and the first and third cyanogen bands, but the second cyanogen band is missing. Unknown lines at $\lambda \lambda 3913,4002,4022$, $4255,4276,4549$, and 4570 are also shown on the spectrograms, and it is suggested that the last six may be related bands, similar to those of cyanogen, due to some substance as yet unknown terrestrially.

Parallax of 23 H Camelopardalis.-From a photographic investigation, Herr Gustaf Strömberg finds that the parallax of $23 \mathrm{H}$ Camelopardalis is $\pi=+0^{\prime \prime} \cdot 127$. $\chi=-0^{\prime \prime} \cdot$ oro, with probable errors of $\pm 0^{\prime \prime} .053$ and $\pm 0^{\prime \prime} \cdot 057$ respectively, where $\chi$ is the relative correction of the aberration constant. These values were obtained by the measurement and discussion of twenty-eight plates taken between October, 1904, and April, 1908, twentythree being employed for the estimation of the difference in right ascension and twentv-five for that in declination (Astronomische Nachrichten, No. 4295, p. 366).
The Stars of the $c$ and ac Subdivisions in the Maury Spectral Classification.- In No. 4296 of the Astronomische Nachrichten Herr E. Hertzsprung discusses the distance, distribution, and probable general characteristics of the stars which in Miss Maury's classification of the "Spectra of Bright Stars" (Harvard) are placed in the subdivisions $c$ and $a c$. From the discussion of their proper motions, parallaxes, \&c., the author finds, among other conclusions, that these stars, among which many of the brightest stars in the heavens are included, are generally at a greater distance and intrinsically brighter than those of the other groups.

The Stars surrounding 59 Cygni.-No. 25 of the Contributions from the Observatory of Columbia University contains the measures of the Rutherfurd photographs of stars surrounding 59 Cygni. The measures are discussed by Prof. Jacoby, and in the final catalogue the positions $(1875 \cdot 0)$, magnitudes, \&c., are given for forty-six stars.

Errors of Double-star Measures.-In Nos. 4298-9 of the Astronomische Nachrichten (pp. 17-39, January 22) Dr. H. E. Lau discusses the systematic errors of doublestar measures, and gives in detail the peculiar errors of a large number of well-known observers. In each case a brief note gives the mean probable error at different distances and in position-angle; the magnitude equation of each observer is also discussed.

\section{ELECTRIFICATION OF RAILWAYS.}

\section{Present Position.}

SINCE the position of railway electrification was last reviewed in these columns, a number of important developments have taken place on the Continent and in America. In England the conversion of steam lines has been slower than was anticipated. On the Continent, however, its spread has been quite as rapid as was expected by any but the too optimistic.

Electrification may be considered under practically the same heads as railways themselves. That is to say, the problem is quite different according to whether the application be to main line, suburban, or purely urban traffic, while the handling of goods traffic introduces an additional consideration.

As regards the advantages of electricity for handling urban traffic there is practically no longer any discussion. Thus most of the purely urban systems in the great capitals of the world, such as the tubes, District, and Metropolitan Railways in London, the Metropolitan in Paris, the subways in New York, and the railways in Berlin and Chicago, so far as they are self-contained, are now electrically worked, steam where previously in use having been replaced.

As regards suburban lines, especially where this is carried over lines which are also used for main-line traffic the process has not been carried so far. There are, of course, plenty of instances where the conversion has taken place both in the neighbourhood of great capitals and in less populous districts. Thus in London the Harrow extension of the Metropolitan and portions of the Great Western and South-Western now use electricity. In New York the New York Central and the New York, New Haven, and Hartford lines are now working electrically, and the Pennsylvania tunnels are being rapidly equipped In Chicago the lllinois Central is now considering the electrification of a large number of suburban lines, while an extension of electric working to most of the suburban lines in the Berlin district will probably take place before long. In Melbourne the Railway Commissioners have recently had before them the whole question of converting their suburban system, upwards of 200 miles, to electric working. In London, however, the application of electric working to the suburban sections of the great main lines has made little progress. The Brighton Company has been engaged for some years in converting a portion of its suburban system between Victoria and London Bridge, and the result of that experiment, both financially and technically, will doubtless have its result upon the other companies. A trial trip was made a few days ago.

No. 2050, VOL. 79] 
There are two principal factors, however, which have somewhat lessened the urgency of the electrification problem on London suburban lines.

\section{Suburban Congestion.}

A few years ago the principal trouble from which the London suburban railways were suffering was the congestion at their termini, and enormous sums of money were consequently spent on enlarging these termini and increasing the facilities for handling suburban traffic. Since that time, however, suburban traffic has received a setback. Although the provision of new facilities, such as tubes and the conversion of horse tramways to electricity, has undoubtedly created a very large new traffic, it has also abstracted a large amount of traffic from the older railways, and by that much has lessened the congestion at their termini. Now it is a recognised fact that the adoption of electric traction is not, as a rule, justified upon the grounds of reducing working expenses alone. It is true that it usually enables working expenses to be reduced as compared with steam working, but the saving is seldom, if ever, sufficient to pay for the capital charges on the new expenditure involved, and to justify these additional traffic is required. This additional traffic may or may not be obtainable. In the case of the NorthEastern Railway, in that of the Liverpool and Southport lines, and in that of the Metropolitan District Railway additional traffic has been obtained, but it remains to be seen, in view of the growing competition of electric tramways and motor omnibuses, whether sufficient additional traffic can be obtained upon the other London suburban lines, like those now being converted by the Brighton Company, for instance.

Take the North London Railway, the receipts of which show a steady diminution. Electrification has been more than once mooted, and even considered, but never, we believe, seriously investigated by the board; such preliminary and superficial investigations as have been made have, it is believed, pointed to the fact that the cost of converting the lines would not be justified, at least at present, by the extra traffic obtainable; whether a complete investigation by an expert competent to decide upon the commercial as well as the technical aspects would show a different result is a moot point. It may be, of course, done when the Euston to Watford line is completed, and electricity is adopted on a part of the NorthWestern sustem, in view of the intimate relations existing between these two companies. Many of those who are most experienced in this question believe that it would materially assist the latter to stem the steady reductions in receipts which have now been taking place for years, while the difficulty of hauling "foreign" trains over the svstem, which Lord Rathmore has mentioned, is one which has been surmounted without difficulty at the other end of the "Outer Circle," where the North-Western trains were until recently hauled from Earl's Court to the Mansion House by electric locomotives.

\section{Direct Current and Single-phase.}

In spite of the differences of opinion between experts as to the relative merits of the different systems of electric traction in use, especially those of the direct-current and single-phase systems, each of which is in reality suited to a different set of conditions, the real problem of electrification at the present time is a commercial one. The fact that in the past the electrical experts have been apt to lay stress upon the technical side, and have in some cases devoted less attention and study to the purely commercial side than it warranted, has undoubtedly made an unfavourable impression upon the railway director and business man. The engineer of the old school was primarily educated with the idea of designing and carrying out undertakings which would reork. Only since the beginning of the present century has it been fully grasped that the engineer, and more especially the electrical engineer, whose opinion is to be worth paying for is the one who can make a trustworthy report upon whether the undertaking will pay.

The growing importance of this aspect of the question is strikingly illustrated in one of the latest reports upon electric traction, that which the Railway Commissioners of Victoria have recently made public. The keynote of this whole report is whether the application of electric traction to the system under discussion is financially justified, and, in the second place only, to determine the best means of applying electric traction if it be justifiable.

More and more it is becoming realised in the railway world that a considerable proportion of the traffic which has been diverted from the railways to tramways and omnibuses is traffic which these latter are more fitted to carry. This diversion of traffic can often be stopped, and in some cases, as has happened on the Tyne, for instance, some of it can even be regained; but in the main, electrification, to be justified, must create fresh traffic, usually that of eight to ten or tweive miles, which is rather beyond the profitable radius of a suburban tramway. Given sufficient inducement to the season-ticket holders, the tento fifteen-mile suburban traffic in the neighbourhood of provincial towns, and the fifteen- to twenty-five mile traffic in the neighbourhood of London, is capable of very considerable expansion. The movement of the daily breadwinner to even greater distances from his work is a steadily growing one.

There is, of course, in addition to this, usually a considerable saving in operating expenses even with the same train mileage. When, as is always found advisable, the train mileage after electrification is increased, the reduction in the working expenses per train mile is very considerable.

There is another cause lessening the urgency of London suburban electrification, and that is the reduction in mainline trains now being effected as the result of working agreenients, which makes suburban working easier.

\section{The Financial Question.}

The Victorian report already referred to shows very clearly and typically the kind of financial change which may be expected to be produced by electrification. This system is a considerable one, with a track mileage of more than 200 and a very dense traffic. The expenses per train mile are $18.9 d$. with steam, and would be $11.0 d$. with electric traction. The total operating expenses with electric traction for the whole suburban system is 27,627 . per annum less than with steam, but when the interest on the new capital outlay is added, the total cost of operating would be $44,79 \mathrm{rl}$. more than with steam. Against this, however, is to be put the additional revenue derived from the improved service, and it is shown that the final result would be a balance in favour of electrification. For some reason or other the figures appear to be based upon a traffic increase of only 5 per cent. as the result of electrification. Why such an exceptionally low figure is taken is not explained, for it is pretty certain from the experience of the District Railway, the NorthEastern Railway, the Manhattan Elevated, and, in fact, almost every svstem which has been converted, that a very much greater increase than this will certainly result.

In addition to the decrease in the suburban traffics, and consequently the terminal congestion, existing a few years ago, the railway companies with termini in London have felt some hesitation owing to the introduction of the singlephase system. The direct-current system which is used on the Underground and for the majority of heavy suburban electric traction schemes is not now the only one possible.

The single-phase system, which is being adopted by the Brighton Company, and which is used on the lines of the New York, New Haven, and Hartford Company, offers certain advantages over direct current, especially where the ultimate extension of electric traction to main lines is possible. It is, however, more expensive to install, assuming the same degree of security and workmanship, needs heavicr rolling-stock, and a greater expenditure of current.

These two causes, together with the natural objection to raising money at the present time and to the desire to wait and see whether the Brighton experiment turns out successful, both financially and technically, have made the question of electrification in the London district fall into abeyance at present. At the same time, it must not be No. 2050, VOL. 79] 
There are two principal factors, however, which have somewhat lessened the urgency of the electrification problem on London suburban lines.

\section{Suburban Congestion.}

A few years ago the principal trouble from which the London suburban railways were suffering was the congestion at their termini, and enormous sums of money were consequently spent on enlarging these termini and increasing the facilities for handling suburban traffic. Since that time, however, suburban traffic has received a setback. Although the provision of new facilities, such as tubes and the conversion of horse tramways to electricity, has undoubtedly created a very large new traffic, it has also abstracted a large amount of traffic from the older railways, and by that much has lessened the congestion at their termini. Now it is a recognised fact that the adoption of electric traction is not, as a rule, justified upon the grounds of reducing working expenses alone. It is true that it usually enables working expenses to be reduced as compared with steam working, but the saving is seldom, if ever, sufficient to pay for the capital charges on the new expenditure involved, and to justify these additional traffic is required. This additional traffic may or may not be obtainable. In the case of the NorthEastern Railway, in that of the Liverpool and Southport lines, and in that of the Metropolitan District Railway additional traffic has been obtained, but it remains to be seen, in view of the growing competition of electric tramways and motor omnibuses, whether sufficient additional traffic can be obtained upon the other London suburban lines, like those now being converted by the Brighton Company, for instance.

Take the North London Railway, the receipts of which show a steady diminution. Electrification has been more than once mooted, and even considered, but never, we believe, seriously investigated by the board; such preliminary and superficial investigations as have been made have, it is believed, pointed to the fact that the cost of converting the lines would not be justified, at least at present, by the extra traffic obtainable; whether a complete investigation by an expert competent to decide upon the commercial as well as the technical aspects would show a different result is a moot point. It may be, of course, done when the Euston to Watford line is completed, and electricity is adopted on a part of the NorthWestern sustem, in view of the intimate relations existing between these two companies. Many of those who are most experienced in this question believe that it would materially assist the latter to stem the steady reductions in receipts which have now been taking place for years, while the difficulty of hauling "foreign" trains over the svstem, which Lord Rathmore has mentioned, is one which has been surmounted without difficulty at the other end of the "Outer Circle," where the North-Western trains were until recently hauled from Earl's Court to the Mansion House by electric locomotives.

\section{Direct Current and Single-phase.}

In spite of the differences of opinion between experts as to the relative merits of the different systems of electric traction in use, especially those of the direct-current and single-phase systems, each of which is in reality suited to a different set of conditions, the real problem of electrification at the present time is a commercial one. The fact that in the past the electrical experts have been apt to lay stress upon the technical side, and have in some cases devoted less attention and study to the purely commercial side than it warranted, has undoubtedly made an unfavourable impression upon the railway director and business man. The engineer of the old school was primarily educated with the idea of designing and carrying out undertakings which would reork. Only since the beginning of the present century has it been fully grasped that the engineer, and more especially the electrical engineer, whose opinion is to be worth paying for is the one who can make a trustworthy report upon whether the undertaking will pay.

The growing importance of this aspect of the question is strikingly illustrated in one of the latest reports upon electric traction, that which the Railway Commissioners of Victoria have recently made public. The keynote of this whole report is whether the application of electric traction to the system under discussion is financially justified, and, in the second place only, to determine the best means of applying electric traction if it be justifiable.

More and more it is becoming realised in the railway world that a considerable proportion of the traffic which has been diverted from the railways to tramways and omnibuses is traffic which these latter are more fitted to carry. This diversion of traffic can often be stopped, and in some cases, as has happened on the Tyne, for instance, some of it can even be regained; but in the main, electrification, to be justified, must create fresh traffic, usually that of eight to ten or tweive miles, which is rather beyond the profitable radius of a suburban tramway. Given sufficient inducement to the season-ticket holders, the tento fifteen-mile suburban traffic in the neighbourhood of provincial towns, and the fifteen- to twenty-five mile traffic in the neighbourhood of London, is capable of very considerable expansion. The movement of the daily breadwinner to even greater distances from his work is a steadily growing one.

There is, of course, in addition to this, usually a considerable saving in operating expenses even with the same train mileage. When, as is always found advisable, the train mileage after electrification is increased, the reduction in the working expenses per train mile is very considerable.

There is another cause lessening the urgency of London suburban electrification, and that is the reduction in mainline trains now being effected as the result of working agreenients, which makes suburban working easier.

\section{The Financial Question.}

The Victorian report already referred to shows very clearly and typically the kind of financial change which may be expected to be produced by electrification. This system is a considerable one, with a track mileage of more than 200 and a very dense traffic. The expenses per train mile are $18.9 d$. with steam, and would be $11.0 d$. with electric traction. The total operating expenses with electric traction for the whole suburban system is 27,627 . per annum less than with steam, but when the interest on the new capital outlay is added, the total cost of operating would be $44,79 \mathrm{rl}$. more than with steam. Against this, however, is to be put the additional revenue derived from the improved service, and it is shown that the final result would be a balance in favour of electrification. For some reason or other the figures appear to be based upon a traffic increase of only 5 per cent. as the result of electrification. Why such an exceptionally low figure is taken is not explained, for it is pretty certain from the experience of the District Railway, the NorthEastern Railway, the Manhattan Elevated, and, in fact, almost every svstem which has been converted, that a very much greater increase than this will certainly result.

In addition to the decrease in the suburban traffics, and consequently the terminal congestion, existing a few years ago, the railway companies with termini in London have felt some hesitation owing to the introduction of the singlephase system. The direct-current system which is used on the Underground and for the majority of heavy suburban electric traction schemes is not now the only one possible.

The single-phase system, which is being adopted by the Brighton Company, and which is used on the lines of the New York, New Haven, and Hartford Company, offers certain advantages over direct current, especially where the ultimate extension of electric traction to main lines is possible. It is, however, more expensive to install, assuming the same degree of security and workmanship, needs heavicr rolling-stock, and a greater expenditure of current.

These two causes, together with the natural objection to raising money at the present time and to the desire to wait and see whether the Brighton experiment turns out successful, both financially and technically, have made the question of electrification in the London district fall into abeyance at present. At the same time, it must not be No. 2050, VOL. 79] 